\title{
Commercial Arrangements and Liability for Crossing Pipelines, Power Cables and Telecom Cables (Connectors) on the Seabed
}

\author{
Lars Olav Askheim
}

A direct consequence of the increasingly interconnected world and offshore energy production facilities - such as platforms producing petroleum and wind farms - is the growing number of crossings between subsea transport assets such as oil and gas pipelines, power cables of various voltages and telecom cables such as fiber-optic cables and any traditional telegraph and telephone cables. In particular in closed-basin seas such as the Mediterranean Sea, the Baltic Sea and the North Sea, the number of crossings has increased exponentially over the years. ${ }^{3}$ As a general rule, each crossing is governed by an agreement, almost invariably called a 'crossing agreement', entered into by the owners.

This chapter focuses on offshore crossings, i.e. crossings occurring on the seabed outside the territorial seas. While the issues are much the same onshore and with a similar need for entering into crossing agreements, offshore agreements have some specificities. For example, the coastal state may have used its jurisdiction to affect the crossing arrangements, influencing the liability and compensation regime. Furthermore, there will most probably be additional types of pipelines, such as water and sewer pipelines on shore. The analysis

1 My colleague Mr. Knut Gjelsten, whose experience in this field exceeds my own, has kindly reviewed this article and provided numerous comments. His input is greatly appreciated, but as always, any errors and omissions are my responsibility.

2 The views expressed in this chapter are personal ones. They have not been approved by my employer Statnett SF, who as the Norwegian transmission system operator for electricity has many existing and future subsea power cables, which are subject to a substantial number of crossings.

3 By way of example, the NordLink power cable between Norway and Germany currently under construction, will have approximately 20 subsea crossings. The North Sea Link (NSL) power cable project between Norway and Great Britain, also under construction, will have approximately 30 subsea crossings. 
in this chapter is restricted to three types of 'connectors' 4 that are mentioned above: oil and gas pipelines, power cables and telecom cables.

Further clarifications in terms of terminology and scope are necessary. The 'intruding' installation will hereafter be referred to as the 'Crossing Connector', the 'incumbent' installation at the crossing point as the 'Affected Connector', and the owners as the 'Crossing Party' and the 'Affected Party' respectively. While the Affected Connector might be buried in the seabed, thereby not necessarily entailing any physical contact between it and the Crossing Connector, the situation will still be deemed a crossing. In a situation where the two connectors are adjacent to one other but without any actual crossing, the owners often enter into a 'proximity agreement' governing their relationship. This type of agreement will not be covered in this chapter. This chapter is based on experience from crossing agreements in the North Sea, most of which involve pipelines and power cables. There might be some regional specificities, including legal traditions, but the issues covered are universal and therefore relevant for other parts of the world. Finally, the chapter takes a practising-lawyer approach, focusing primarily on practical issues.

Project specificities constitute important starting points. The physical aspects of crossings are fascinating, particularly as work will be carried out on the seabed, possibly at a depth of hundreds of metres. The dark environment and substantial water pressure require the use of very specialized equipment, largely operated remotely from vessels on the surface. While telecom cables usually merely rest on the ocean floor, power cables are generally buried (below the seabed). For oil and gas pipelines, both approaches are adopted. Thus, the design of crossings will vary, depending on the types of connectors involved, their vulnerability and other factors. For each type of crossing scenario, fairly standardized solution concepts have been developed. If the Affected Connector has a free span (i.e. hanging unsupported in the sea) at the crossing point, the parties need to agree on a specific solution addressing the particular concerns free spans create.

This chapter starts by reviewing the relevant provisions under the United Nations Convention on Law of the Sea (UNCLOS) (Section 2). It continues by identifying the different interests of the parties involved (Section 3), before reviewing in detail the main features and provisions of crossing agreements

4 My choice of terminology is inspired by the term 'interconnector' used in the European Union (EU) regulatory framework for cross-border exchange of gas and power, designating gas pipelines and power cables between Member States (the Electricity Regulation and the Electricity Directive, as well as the Gas Regulation and the Gas Directive). 
(Section 4). The next sections focus on the installation phase (Section 5), and importantly, the liability and indemnity regime applied by the crossing agreements (Section 6). The occurrence of 'new situations' after completion of the installation is envisaged (Section 7). The chapter ends with some concluding remarks (Section 8).

\section{International Law Aspects: Relevant Provisions in UNCLOS}

\subsection{Applicable Regime on the High Seas}

On the high seas (UNCLOS, Part VII), pursuant to Articles 87 and 112(1), all states have the right to lay cables and pipelines. This includes the right to lay new pipelines and cables that cross existing cables and pipelines, without the need for consent. The opposite alternative, in the view of this author my view, would give the Affected Party more power than necessary to adequately protect his interests. Further, the Crossing Party usually has very few practical alternatives to crossing the Affected Connector, implying that the Affected Party would have the power to veto beneficial projects. It would also be contrary to the principle of freedom of the seas if the Affected Party should be regarded as an incumbent with quasi-property rights to the seabed.

However, the Crossing Party will have to give due consideration to the Affected Connector, as provided for in Article 79(5), which also applies to the high seas (see Art. 112(2)):

When laying submarine cables or pipelines, States shall have due regard to cables or pipelines already in position. In particular, possibilities of repairing existing cables or pipelines shall not be prejudiced.

Article 114 states some basic principles for liability:

Every State shall adopt the laws and regulations necessary to provide that, if persons subject to its jurisdiction who are the owners of a submarine cable or pipeline beneath the high seas, in laying or repairing that cable or pipeline, cause a break in or injury to another cable or pipeline, they shall bear the cost of the repairs.

Several principles can be identified in this provision. The first principle is the one of strict liability, since there is no requirement for wilful misconduct or negligence. The second principle is that the provision is neutral between the 
Crossing Party and the Affected Party, in the sense that it applies to both: if one of them causes damage to the other, it is liable. The third principle is that the provision pertains only to repair costs, which means that other losses, such as loss of revenue, are not protected.

\subsection{Applicable Regime in the Exclusive Economic Zone}

With respect to the exclusive economic zone (UNCLOS, Part v), the same rules for pipelines and cables apply as for the high seas (see Article 58 (1) and (2)). It must be noted that the interests of the coastal state have been given some protection in paragraph 3 , however this does not seem very relevant in the context of crossing agreements:

In exercising their rights and performing their duties under this Convention in the exclusive economic zone, States shall have due regard to the rights and duties of the coastal State and shall comply with the laws and regulations adopted by the coastal State in accordance with the provisions of this Convention and other rules of international law in so far as they are not incompatible with this Part.

\subsection{Applicable Regime on the Continental Shelf}

On the continental shelf (UNCLOS, Part VI), the liability regime established in Article 114 will still apply. However, there are significant changes with respect to the laying of pipelines and cables. First, the coastal state has broad jurisdiction over pipelines and cables placed in its territorial waters or used for the exploitation of the continental shelf (Article 79(5)). Second, while the principle of free laying of pipelines and cables is maintained for pipelines and cables crossing its continental shelf (Article 79(1)), the coastal state may protect its interests relating to exploitation of the continental shelf and the prevention of petroleum pollution (Article 79(2)), but may not impede laying or installation. Third, the course of the pipeline or cable is subject to consent from the coastal state (Article 79(3)).

Before going into the content of the crossing agreements, it is beneficial to review the interests of the parties.

The main concern of the Affected Party with respect to crossings is that the Affected Connector is covered for damage or exposure to a higher risk of damage resulting from the Crossing Connector or the installation work. Repair 
costs are substantial, particularly in terms of use of vessels and other marine operation costs. Repairs will consume considerable time, as they require comprehensive planning and the mobilization of specialized equipment/vessels, and may be heavily dependent on weather conditions, including seasonal 'weather windows'.

In addition to covering the repair costs, the Affected Party will also suffer a financial loss due to the Affected Connector being unavailable for its intended use. The amount of the loss will depend on the capacity of the Affected Connector and the economic value of that capacity. In comparison, the value of capacity in telecom cables will generally be substantially lower than the value of capacity in the connectors transporting energy (petroleum, power). The impact of the Affected Connector becoming unavailable will also depend on the redundancy, if any, in the networks with which the Affected Connector is affiliated. It would then be a question of whether the 'traffic' could be rerouted through other connectors. Due to the relatively high costs of subsea connectors, redundancy will tend to be much lower than for onshore connectors, so there will be a considerable exposure for the Affected Party, through loss of revenues, or compensation payable to purchasers of capacity. And even if the Affected Party succeeds in protecting himself against this, there will be a socio-economic loss. Finally, there may be a significant pollution risk relating to oil spillage from a damaged oil pipeline.

The interests of the Crossing Party mainly relate to the Crossing Connector. The costs and loss related to damage to it are much the same for the Affected Party as for the Affected Connector, as described in the previous paragraph, but the risk of causing damage to the Crossing Connector is obviously much smaller. However, the fact that the Affected Connector is situated in international waters does not mean that fundamental legal principles regarding the protection of property belonging to others do not apply. As the newcomer on the scene, the Crossing Party should respect the fact that the Affected Connector is already on site and will have to be given appropriate consideration. Furthermore, once the installation of the Crossing Connector has been completed, the Crossing Party will undoubtedly expect to benefit from the same crossing principles with respect to any subsequent newcomers that cross its own connector. Thus, the combination of those principles and obligations create a positive environment between the parties.

After the crossing has been completed, a new risk scenario emerges in the crossing area. For the Affected Party, access to the Affected Connector in the event of repair or maintenance work becomes more difficult, in particular directly underneath the Crossing Connector. For the Crossing Party, the 
existence of the Affected Connector will impede repair and maintenance work to some extent.

\section{$4 \quad$ Crossing Agreements in a Nutshell}

The parties to the crossing agreement will be the Affected Party and the Crossing Party, but several other companies will also have a direct interest in the content of the agreement, and particularly those affiliated with the Crossing Party. These interested third parties will typically be lenders, insurance providers, and the company that will carry out the installation of the Crossing Connector under contract to the Crossing Party.

\subsection{Main Features}

The main features and issues in a crossing agreement can be summarized as follows (issues that are not always addressed are marked with an asterisk):

- Identification of the crossing point;

- The crossing angle, i.e. the angle between the Crossing Connector and the Affected Connector at the crossing point;

- The Affected Party approves the crossing, either based on (i) an agreed technical solution in an appendix, or, more rarely, on (ii) a defined design process, the result being subject to final consent;

- Definition of a time slot for the installation;

- Steps before installation, i.e. sharing of data on the Affected Connector, design criteria and process, etc., notification prior to start of installation;

- The installation work itself, including representatives, notifications, standard of work, emergency procedures;

- Follow-up work, including preparation of as-installed documentation;

- Liability and indemnity, including basis for liability, extent of liability, liability caps;

- Insurance requirements*;

- Future repair and maintenance;

- Upgrading and reinvestment*;

- Crossing Connector projects with crossings*;

- Decommissioning*.

With respect to the contract period, this is often left open. It is assumed that the crossing agreement will apply as long as the crossing exists.

Naturally, there will also be 'boiler plate' type provisions dealing with issues such as confidentiality, waivers, amendments, notices, all of which are found in most commercial contracts. 


\subsection{Model Agreements}

There is no universal, fixed format for crossing agreements. However, experience shows that it is fruitful to distinguish between different crossing scenarios, depending on the type of connector involved. As demonstrated in the table below, substantial efforts have been made in developing model agreements in the North Sea.

\section{Affected Connector}

\section{Pipeline Telecom cable Power cable}

\begin{tabular}{lllll}
\hline New & Pipeline & IS / CS & $?$ & $?-$ ad hoc? \\
Connector & Telecom cable & $?$ & CS & $?-$ ad hoc? \\
$\cdot$ & Power cable & CS / based & CS & $?-$ ad hoc? \\
& & on IS & & \\
\hline
\end{tabular}

IS = Industry standard

CS = Company standard - might apply for the whole company or just for a single project

$?=$ This author is unaware of any specific standards applying to this situation or whether standard from other crossing types are adopted.

In Great Britain and Norway, the industry associations (UK Oil \& Gas Industry Association and Norwegian Oil and Gas) have produced model agreements for pipeline crossings. ${ }^{5}$ Oil companies may also have established company standards. In the North Sea, the major telecom operators have produced their own company standard agreements; these are far from identical but are still quite well-aligned.

The company standards have tended to favour the interests of the Affected Party. They are generally drawn up by incumbents, some of whom own or operate a large number of connectors. However, the drafters of some of these standards have wanted to avoid a situation where each crossing has to be negotiated extensively. Given that the draft is frequently heavily in favour of the Affected Party, one wishes to avoid the Crossing Party disputing every deviation

5 For the UK, for Oil and Gas UK, see 'Pipeline Crossing Agreement \& Proximity Agreement Pack October 2015' (OP115), available at: <http://oilandgasuk.co.uk/product/pipeline -crossing-agreement-proximity-agreement-pack-october-2015/>. For Norway, for Norwegian Oil and Gas, see 'Norwegian Oil and Gas recommended Model Agreements for use of Pipeline to pipeline, Tie-in, Crossing, Proximity, Confidentiality', available at: $<\mathrm{https} / / \mathrm{www}$ .norskoljeoggass.no/drift/standardkontrakter-og-modellavtaler/modellavtaler/>. 
from the draft. Instead, they have prepared a model agreement that is not necessarily totally balanced but is largely within acceptable limits for the Crossing Party. With such a standard, it will be easier to insist that 'no variations are accepted' - or that variations may be acceptable but will require substantial internal processes over a lengthy and undetermined period of time.

The understanding of this author is that the development of industry standards in the petroleum sector has been based on the awareness that today's Crossing Party may become tomorrow's Affected Party in a new crossing, elsewhere at a later time. Thus, a more natural balance can be obtained in a longer run.

The UK standard pipeline crossing agreement is structured as follows:

- Main body of the agreement. It numbers approximately 20 pages, includes contractual conditions and signature pages. Interestingly, on some issues, the text provides alternative solutions.

- Schedule 1: Plan of the Route of the Crossing Pipeline

- Schedule 2:

- Part (A) Scope of Work

- Part (B) Plans, Specifications, Construction Procedures and Risk Assessments

- Part (C) Specimen Composite As-built Survey Drawing

- Part (D) Construction Operations and Location of the Representative

- Schedule 3: Facilities for the Representative Offshore

The Norwegian standard pipeline crossing agreement has a slightly different structure:

- Special Terms and conditions. This is a short, top-level document of 4 articles only. It contains consent to the crossing, list of the contract documents, a few basic definitions and signature page.

- Article 1- Definitions, Agreement Documents and Interpretation

- Article 2 - Consent to Pipeline Crossing

- Article 3-Capacity of the Parties

- Article 4-Representatives and Notices

- Appendix A General Terms and Conditions for Pipeline Crossing (approximately 15 pages)

- Appendix B Planned Route of the Crossing Pipeline and Crossing Point(s)

- Appendix C Laying Operation

\subsection{The Parties' Motivation for Entering into Crossing Agreements}

As indicated above, the Crossing Party does not need consent from the Affected Party. More generally, there is no legal obligation to enter into a crossing 
agreement with regard to crossings in international waters. ${ }^{6}$ In practice, most crossing situations entail the signing of a crossing agreement.

In the view of this author, the first major benefits from having a crossing agreement are clarity and predictability. The parties will know their legal situation, which is obviously an advantage for both. The Crossing Party can assess the legal risks relating to the crossing, and the Affected Party will have some influence over how and where the crossing shall take place. In addition, by having an agreement with a choice of law provisions, the parties avoid potentially difficult choice of law issues that may arise in the absence of an agreement. After all, lex loci delicti, which is the general principle for tort claims in private international law, ${ }^{7}$ does not provide much guidance for crossings in international waters.

Secondly, a crossing agreement may establish solutions that differ from the ones provided in UNCLOS. A very important example in this respect is the introduction of maximum amounts of liability. There is no basis for such liability caps in UNCLOS, but there is a clear commercial need, not just for the Crossing Party, but also for his lenders and his insurance providers. ${ }^{8}$

A third advantage is that the crossing agreement can be made much more specific and detailed than the fairly short and general language in UNCLOS. The parties will still adhere to the principles found in UNCLOS, but they will define how these principles shall apply to the crossing at hand. The prime example of this is the often quite detailed body of provisions on cooperation before, during and after the construction work. These are much more operational and practically appropriate than the general language in Article 79(5) on the consideration to be given to the Affected Connector.

Closely related to this is the parties' opportunity to address issues that are outside the provisions of UNCLOS. The liability provisions of Article 114 only cover costs of repair to the Affected Connector and the Crossing Connector. The parties may also find it appropriate to provide solutions for damage to

6 There may be nationally based exceptions relating to owners of pipelines and cables which enter into territorial waters (and thus do not just cross the seabed outside these limits, or owners of pipelines and cables used for the exploitation of resources on the continental shelf.

7 The essence of this is that the tort claim is governed by the law of the place where the key elements in the tortious act occurred. There is substantial legal practice and theory here, but for reasons of space, I will not go further into these issues.

8 The construction of the New Connector will often be covered by project insurance (CAR = Construction All Risks) which will regularly include liability cover, including liability towards the Affected Party. For these reasons the providers of CAR insurance will attach great importance to the existence and contents of crossing agreements. 
other assets belonging to them, damage to their personnel, as well as third party liability. Further, no insurance requirements exist in UNCLOS either.

All these advantages can be condensed into a single observation: the negotiations for a crossing agreement create an opportunity for the parties to find more effectual solutions than those that might have been adopted if the Crossing Party had simply proceeded on his own. The solutions can be based on the specifics of the crossing itself and the interests of the parties.

\subsection{Timing for Entering into a Crossing Agreement}

In projects for a new connector, it will be necessary at an early stage to clarify issues such as the type of crossings to be made, with appropriate details of the existing connectors and their owners. This will partly be a desktop exercise based on available information, supplemented by information from the owners of known or suspected connectors. Furthermore, data from the early seabed surveys will confirm the existence of a crossing situation and indicate any additional crossings. It may be a bit surprising, but not all existing connectors are properly documented, and some of them may no longer be known even to their owners.

At this stage, it is also beneficial to identify any 'dead' connectors, i.e. connectors that are no longer in use and for which there is no plan to make further use of them. The connector project will not aim to enter into crossing agreements for such connectors even if the historical owners were identified. Such connectors are usually disregarded for installation purposes and are regarded as having been abandoned by their owners, who thereby are deemed to have relinquished ownership.

When there is a real crossing situation, it is advantageous for a connector project to enter into crossing agreements at a fairly early stage, particularly if there are third parties with substantial interests in them. This is obviously the case when construction is to be financed on a project-finance basis. Under this approach, the crossing agreement will most likely only identify the crossing point, while the design of the crossing itself and the installation methods and procedures will be determined at a later stage.

However, in practice, many crossing agreements tend to be entered into fairly late. This allows for the involvement of the installation company selected by the Crossing Party and which will carry out much of the physical work. The insights and inputs from the installation company are obviously valuable for the successful and timely completion of the project. The detailed crossing design can be appended to the crossing agreement. It might also be difficult to convince the Affected Party to engage in quick negotiations if the laying of the crossing is several years in the future. 
In some instances, there is a two-stage process, with an early quasiagreement: once the contact has been negotiated between the parties, the Affected Party will issue a short 'letter of no objection'. This letter usually refers to the standard technical requirements of the Affected Party and its standard crossing agreements, both of which are attached to the letter. In the letter, the Affected Party states that, on the basis of compliance with those two documents, it has no objection to the crossing. It is unlikely, and not intended, that this letter is legally binding. However, it still serves a useful purpose by indicating the basis on which the Affected Party is ready to enter into a crossing agreement. It also provides some assurance to the Crossing Party and parties related to it, such as lenders and insurers.

\subsection{Pre-installation Phase and Related Provisions}

The objective is here to facilitate the development of a good crossing solution, where the interests of the Affected Party are duly protected. Among the common topics covered are exchange of information about existing infrastructures and design of the crossing;

The content of the provisions concerning the pre-installation phase will depend on whether the parties have chosen an 'early' or 'late' crossing agreement, as discussed in Section 4.4. If the 'early' approach has been chosen, the Affected Party will need to provide information about the Affected Connector, usually covering existing documentation and without involving any liability for the correctness and completeness of the information submitted. Under the 'late' approach, the crossing agreement will usually only describe the detailed crossing design (prepared by the Crossing Party or a subcontractor, approved by the Affected Party), without any reference to information, if any, provided by the Affected Party.

The crossing agreement places the responsibility for the design of the crossing on the Crossing Party. This will also include installation methods and procedures. There is also almost invariably a requirement for a pre-installation survey to be carried out. The Crossing Party will have to produce appropriate drawings and progress schedules and may also be obliged to prepare risk assessments and/or other quality assurance/quality control documentation. The anchoring patterns for the installation vessel is a particular concern. The crossing agreement may contain references to 'good engineering practice' or similar expressions, although such requirements will usually apply even if they are not explicitly mentioned. 
Following this, the Affected Party has the option of approving or disapproving the corpus of documents submitted. The Affected Party will be given a maximum time period for this, and it is usually stated that consent cannot be unreasonably withheld or delayed.

In some instances, the crossing solution entails that the Crossing Connector is installed underneath the Affected Connector. This usually requires cutting or lifting the Affected Connector so that the latter will be out of service for some time. The Affected Party might want to insist in the agreement that any work done directly on the Affected Connector be carried out by his contractor, or at least that there must be only one contractor commissioned to do all work, one who is qualified to perform work on both connectors.

To the extent approvals from public authorities are necessary, the Crossing Party will assume the task of obtaining them. In practice, it is usually stated that the party is obliged to ensure compliance with all applicable legislation.

The choice of contractor lies with the Crossing Party, but the crossing agreement might set some specific stipulations in terms of qualification and experience requirements.

\subsection{The Installation Work Itself}

The installation work is the obligation of the Crossing Party and is to be carried out at his cost and risk. Before installation starts, the Crossing Party must respect a minimum notification period.

The crossing agreement will often require, in a standard clause, that the Crossing Party conduct all installation work in compliance with general standards of care and reason. This concept can be expressed in various ways, such as 'good oil industry practice' or 'acting as reasonable and prudent operators' to give only two examples.

The installation of the Crossing Connector will be preceded by some preparatory works, including deepening the position of the Affected Connector in the seabed, as well as building trenches, foundations, ramps, and/or bridges for the Crossing Connector. When the Crossing Connector has been put in its proper place, the Crossing Party will have to carry out any protective measures agreed in advance, such as the placing of protective materials - mats, rock, other materials - over the Connectors.

Many crossing agreements will allow the Affected Party to have a representative on site during installation work. This representative is usually given observer status - expressly stated in the crossing agreement - and shall not be called upon to give approvals or act as a representative of the Affected Party. However, the representative may have the right to stop the installation work under certain circumstances, such as emergencies or risk of damage to the Affected Connector. 
In the event the Affected Connector is damaged during installation, a situation arises for which it is difficult to make proper provisions in advance. The crossing agreement might specify that any repair work must be carried out by the Affected Connector or by a contractor chosen by him. The costs will be at the expense of the Crossing Party, as discussed in more detail in Section 6. The crossing agreement might also state that the protection and repair of the Affected Connector shall have priority over the installation work, if the Affected Party so requests. The Affected Party might be entitled to request assistance from the Crossing Party, for example to use the vessel and marine equipment the Crossing Party has on site. However, this cannot be strictly required. The suitability of the vessel, equipment and workmanship should fall under the provision stipulating appropriate tools and materials, and to a 'best efforts'-type of reservation.

The Crossing Party will be subject to reporting obligations on a cyclical and/ or more or less current basis during the installation period.

\subsection{Follow-Up Activities}

After completion of the physical installation work, crossing agreements often provide for some additional obligations for the Crossing Party. While the content of those obligations will vary, the following issues seem to be most pertinent:

- An as-installed survey shall be carried out by the Crossing Party and made available to the Affected Party at no cost. Some crossing agreements introduce an approval mechanism here, implying that the Crossing Party may have to re-do the survey in full or in part. The purpose of the survey is both to document the current physical situation at the crossing point and in the area around it, and to verify that the Crossing Party has carried out the installation work in compliance with the terms of the crossing agreement.

- The as-installed survey will be included in the as-installed documentation, which shall also be provided to the Affected Party.

- Rectification of any deviations, whether identified through an as-installed survey or not, shall be carried out by the Crossing Party.

- A 'quarantine period' of some months will apply, during which all defects identified in the Affected Connector will be deemed to have been caused by the Crossing Party, entailing that any related financial loss will be borne by the Crossing Party. Such a period should be seen in conjunction with the liability and indemnity provisions of the crossing agreement, which will be reviewed below. 


\subsection{Balancing Parties' Interests and Capabilities: General Matters}

The liability and indemnity provisions are often seen as the core of the crossing agreement in a legal perspective. They will address not only the direct tort liability of the parties between themselves, but also the extent to which a party can seek indemnification from the other party in the event of third-party claims.

Concerning liabilities between the parties, there are both the costs of repairing any damage to the Affected Connector and any follow-on losses such as loss of revenue, exposure under contracts with users of the Affected Connector, and in some cases also exposure under regulatory mechanisms relating to the unavailability of the Affected Connector. ${ }^{9}$

The number of potentially affected companies and individuals can be quite large. The first set of third parties is related to one of the parties in some manner, and includes inter alia affiliates of the parties, contractors and subcontractors, as along with employees of all these entities. These will be referred to as the 'Affected Group', and the equivalent group on the other side as the 'Crossing Group'.

The second set of third parties is occasionally referred to as 'true' third parties and is quite diverse. It can include owners of other facilities in the vicinity of the crossing point, shipowners, fishermen, users of the Affected Connector, etc. A special type of claims relates to pollution liability, which in practical terms is significant mainly for oil and gas pipelines.

The liability and indemnity provisions cannot be considered in isolation of the insurance arrangements. On a superficial level, the insurance arrangements can be seen as designed to cover the liabilities and indemnities assumed by a party in the crossing agreement. However, in the view of this author, it is more productive to see it the other way round: to the extent that an exposure is protected by insurance, it does not really matter which of the parties is responsible under the liability and indemnity provisions. ${ }^{10}$ Consequently, the financial liability exposure should be assumed by the party who has the best access to insurance and can obtain the most favourable premiums and other conditions, including deductibles. The parties should attempt to avoid a situation where both carry insurance for the same potential event, as this is not efficient in terms of premiums, i.e. the Affected Party under his general

9 This exposure can arise for connectors that are part of an open access network with tariffs developed under public regulation.

10 The liability and indemnity provisions will still be relevant for any deductibles and exclusions from the insurance cover. 
insurance, the Crossing Party under insurance relating to his project in general or to the crossing itself. 'Double insurance' can also create disputes as to which insurer shall pay.

Given UNCLOS Article 114 and the incumbent position of the Affected Party, it should not come as a surprise that in a crossing situation, as a general rule, the Crossing Party will carry the liability in the event of damage to the Affected Connector, howsoever caused. However, in practice this general rule is rarely applied to its full extent and exceptions are made. Based on the review of several crossing agreements, the impression given is that there is considerable variation on that point.

\subsection{Specific Liability and Indemnity Issues}

The first and most fundamental issue is the extent, in time and space, of the special compensation regime the crossing agreements establish. Most of them relate this to the installation operation, either by simply looking at this as a period of time, or by requiring a link (with language like 'arising out of or in connection with' the work or the installation) between the installation and the damage.

The next issue is the damage the special compensation regime applies to. Damage to the Affected Connector is obviously included, but in practice the regime will also apply to other forms of damage to property and personnel in the belonging to the Affected Group, as well as claims from third parties.

Damage might not necessarily manifest itself during the installation period. It may also be that although the damage occurred during installation, it only comes to the attention of the parties at a later time. In order to give protection to the Affected Party in this respect, many crossing agreements establish what can be referred to as an 'extended liability period'.

The effect of the extended liability period, in its purest form, is that damage discovered during the period will be deemed to relate to the installation, and thus be covered by the special regime, regardless of actual cause. In some instances, this is softened into a presumption that the Crossing Party can rebut if he can produce adequate evidence that the damage was not caused by him. In practice, this will mean that he will have to substantiate that a person specifically caused the damage, or that the damage is caused by a particular type of activity, for example trawling. The extended liability period can be quite long -6 to 24 months is not unheard of. It can start when installation work is completed or can be linked to the delivery or approval of the as-installed documentation.

The next issue is the basis for liability. In contract practice, the prevailing, sufficient basis for liability is that the Affected Connector is damaged. It is therefore not a necessary condition that the damage is caused by the Crossing 
Party or any other individual or company for which he is responsible, such as contractors, affiliates or employees of such companies. However, in a few crossing agreements, causation is only a presumption that the Crossing Party may attempt to rebut, and the burden of proof will lie with him. It seems appropriate that the Crossing Party should be deemed liable in the event of inherent defects in the Affected Connector.

Is the principle of liability for the Crossing Party maintained also in the event that it can be substantiated that the damage was caused by the Affected Party or the Affected Group? This may be regarded as unreasonable, and many legal systems will not accept such a principle when there is serious misconduct. There are several ways to attempt to resolve this, and the proper solution depends on the governing law chosen by the parties. One element here is the gravity of the acts of the Affected Group, where an exception will be made in cases of wilful misconduct, possibly also extending to gross negligence. The other element is the identity of the persons in question: some crossing agreements limit the exclusion in this context to such actions taken at a management level.

It is customary to agree on a maximum amount of financial responsibility for the Crossing Party. The amount will obviously depend on several factors, including probability of damage, an expected range of loss and insurance costs. In Norway, in respect of crossings involving pipelines, a global cap amount of USD 100 million for the crossing is prevailing and is reflected in the industry standard. Still in Norway, the cap amount for crossings involving telecom cables tends to be significantly smaller, but here the cap often works at two levels: one cap for each incident, and a higher total cap.

Another important issue is whether indirect/consequential losses caused by damage to the Affected Pipeline are excluded. Here there is no generally prevailing solution. In the two oil industry standards referred to in Section 4.2, the Crossing Party is liable within the limits of the liability cap also for consequential damage. This is contrary to normal practice in most commercial contracts. For crossings involving telecom cables, the crossing agreements made available seem in general to take the opposite approach, excluding consequential loss.

Pollution liability, including both damages caused and clean-up costs, is particularly relevant for oil pipelines. Some crossing agreements involving oil pipelines exclude such liability from the special regime and will instead generally provide that financial losses due to spillage/leakage of oil from an oil pipeline, will be assumed by the owner of the pipeline in question. Exceptions might apply in the event of gross negligence or wilful misconduct. 


\section{$7 \quad$ Dealing with the New Situation in the Post-completion Phase}

After completion of the installation, a new situation is created with two connectors in the same area and various protection arrangements in place. Both connectors are vulnerable with respect to the performance of work on the other connector. For the connector located underneath, there is an obvious additional challenge of obtaining access.

In the normal course of business, there should be little need for physical work in the crossing area, as the risks of defects in the connectors themselves are limited. Then, only a small part of the connector is located in the crossing area. Meanwhile, defects can occur, and one or both connectors could be damaged by outside forces. Some crossing agreements do not address this situation at all, which might be explained by a lack of foresight, deliberate omission after difficult negotiations, or just a business judgment that the risk is fairly small and can be assumed by the parties if it should arise. However, the consequences of defects can be far-reaching. Consequently, rules are needed that define the rights and obligations of the parties in such situations.

Most agreements do not distinguish the solutions depending on the parties, meaning that the provisions are symmetrical and that the Affected Party will have the same position as the Crossing Party. The Affected Party can thus not expect to avoid any subsequent costs deriving from the crossing merely due to the fact that he was the first in the area, even if his situation can be said to be worse than that of the Crossing Party. However, it may happen that the Affected Party obtains some concessions in the event of difficult access or temporary removal of the Crossing Connector, typically due to some particular circumstances.

An important element of the crossing agreements will relate to the physical delimitation of the area in which the post-completion provisions apply. This area is usually defined by a given radius around the crossing point. Outside that area, any obligation on the parties must be based on other legal grounds in the crossing agreement.

Some types of work do not involve actual physical contact with the seabed or the Connectors, such as surveys carried out by remotely operated vehicles (Rovs) (miniature, unmanned submarines controlled from the surface). The tendency is that each party can carry out intentional work, but potentially subject to a notification requirement.

Other types of work will involve physical presence, such as the use of anchors and other mooring equipment, as well as ploughs or other equipment affecting the seabed. For those physical works, several approaches are followed in practice. One approach is to make all such work conditional upon a separate agreement being entered into. Obviously, this approach will give the other 
party a strong negotiating position. An alternative approach is to retain the concept of consent but soften it by stating that consent shall not be unreasonably withheld. This language is not very precise, but it is hard to see that it is possible to improve it significantly. A third approach is to state that the parties shall enter into a new crossing agreement which must reflect the first crossing agreement. With this approach, the status of 'intruder' in the new crossing is determined independently of the status in the first crossing agreement. Thus, the Affected Party in the second crossing agreement could be the Crossing Party in the first crossing agreement. Regardless of the approach, it is convenient to have an exception for emergency situations, where there is insufficient time to obtain agreement or consent. The costs of such work are generally to be assumed by the party triggering the work, even if some of them relate to the connector of the other party.

Some crossing agreements foresee a particular need for changing the configuration of the crossing. For example, the Affected Connector which originally lies underneath the Crossing Connector may instead cross over it at a later stage. The contents of such change in crossing configuration clauses will vary. One approach is to modify the provisions on consent requirements to facilitate the changes but also clarify the cost consequences, e.g. that the Affected Party will assume all costs.

Finally, any work in the crossing area after completion of installation will generate liability and indemnity issues, governed either by the existing crossing agreement or in a new agreement to be entered into.

Crossing agreements are commonly seen as practical arrangements, with limited interest from a commercial point of view. In companies with a significant portfolio of subsea connectors, crossing agreements tend to be dealt with by a small group of specialists who are highly experienced but with a strong preference for their established practices and model agreements/clauses.

For the reasons stated, agreeing on a crossing agreement can be a fairly long, but not necessarily a very complicated process. There is little general controversy and the industry shares some common practices along with the joint need to realise respective projects. However, if a Crossing Party faces many crossings in a project, this will create additional challenges in managing the entire process.

Crossing agreements constitute a fascinating example of the conflict between incumbents and intruders in relation to the use of the same seabed 
area. The basic question remains: how to strike the balance between the interests of the party who first moved into an open area and the interests of newcomers. UNCLOS provides the main principles, but as the review of contract practices has shown, many additional provisions are needed and different solutions must be found to solve possible conflicting situations. Therefore, there are significant benefits to be derived by both parties agreeing on a crossing agreement. Not least, the potential 'reversal of roles' in the post-completion phase regarding subsequent crossings/projects will make the parties more inclined to seek balanced solutions than if the crossing in question was seen as an isolated case. 